\title{
Downregulation of Hsp70 inhibits apoptosis induced by sialic acid-binding lectin (leczyme)
}

\author{
TAKEO TATSUTA ${ }^{1}$, MASAHIRO HOSONO ${ }^{1}$, YUKIKO OGAWA ${ }^{2}$, KYOKO INAGE ${ }^{1}$, \\ SHIGEKI SUGAWARA $^{1}$ and KAZUO NITTA ${ }^{1}$

\begin{abstract}
${ }^{1}$ Division of Cell Recognition Study, Institute of Molecular Biomembrane and Glycobiology, Tohoku Pharmaceutical University, Sendai 981-8558; ${ }^{2}$ Divisions of Functional Morphology and Microbiology, Department of Pharmacy, Faculty of Pharmaceutical Science, Nagasaki International University, Sasebo, Nagasaki 859-3298, Japan
\end{abstract}

Received August 6, 2013; Accepted September 23, 2013

DOI: $10.3892 /$ or.2013.2814

\begin{abstract}
Heat shock proteins (Hsps) are molecular chaperones that maintain homeostasis of organisms. In regards to the Hsps, many studies have investigated the structure, expression, localization and functions of Hsp70 and Hsc70 including expression in the glycosphingolipid-enriched microdomain (GEM) on the cell surface and involvement in cell death. Sialic acid-binding lectin (SBL) isolated from oocytes of Rana catesbeiana is a multifunctional protein which has lectin activity, ribonuclease activity and antitumor activity. SBL has potential as a new type of anticancer drug, since it causes cancer-selective induction of apoptosis by multiple signaling pathways in which RNA is its target; and the participation of the mitochondrial pathway and the endoplasmic reticulum (ER) stress-mediated pathway has been suggested. It has also been suggested that receptor(s) for SBL (SBLR) may exist in the GEM on the cell surface. In the present study, we studied the possible involvement of Hsp70 and Hsc70 in SBL-induced apoptosis. We showed that Hsp70 and Hsc70 were expressed on the P388 cell surface similar to SBLR, and their distribution in cells dramatically changed immediately prior to the execution of apoptosis following stimulation of SBL. Functional study of Hsp70 revealed that decreased expression of Hsp70 diminished the apoptosis induced by SBL. It is suggested that Hsp70 participates in the antitumor effect of SBL.
\end{abstract}

\section{Introduction}

In response to various types of stress, cells activate a highly conserved heat shock response in which a set of heat shock proteins (Hsps) are induced. These proteins play important

Correspondence to: Professor Kazuo Nitta, Division of Cell Recognition Study, Institute of Molecular Biomembrane and Glycobiology, Tohoku Pharmaceutical University, 4-4-1 Komatsushima, Aoba-ku, Sendai 981-8558, Japan

E-mail:knitta@tohoku-pharm.ac.jp

Key words: lectin, ribonuclease, leczyme, apoptosis, Hsp70, Hsc70 roles in cellular repair and protective mechanisms. There are 2 types of Hsps, i.e., stress-inducible and constitutive types. In addition, it is well known that Hsps act as molecular chaperones to maintain the homeostasis of organisms (1). Recently, much information has become available on the specific role of individual Hsps. In particular, there are many significant reports regarding $\mathrm{Hsp} 70$ family member proteins that are closely involved in cell death. It has been reported that Hsp70 inhibits apoptosis by hindering the activation of JNK (2), or by preventing recruitment of procaspase- 9 to the Apaf-1 apoptosome (3). In contrast, Hsp70 promotes apoptosis. For example, overexpression of Hsp70 was found to enhance TCR and fas-mediated apoptotic cell death (4). Among the Hsp70 family, Hsp70 and the constitutively expressed 73-kDa heat shock cognate protein (Hsc)70 have been found to be located in the cytosol and to migrate to the nucleus after specific stress (5), but are also expressed on the cell surface and interact with various types of receptors (6-8). It has also been reported that Hsps such as Hsp70 and Hsc70 are expressed in the glycosphingolipid-enriched microdomain (GEM) on the cell surface $(9,10)$.

Sialic acid-binding lectin (SBL) isolated from Rana catesbeiana oocytes was identified as a lectin, since SBL agglutinated certain types of tumor cells and the agglutination was inhibited by glycoprotein or ganglioside-containing sialic acid (11-13). Agglutination induced by SBL was observed only in tumor cells but not in normal red blood cells and fibroblasts (13). The amino acid sequence of SBL shows that it has homology to members of the RNase A superfamily, and it has been revealed that SBL has pyrimidine base-specific ribonuclease activity (14-17). The antitumor effect of SBL was reported using P388 and L1210 murine leukemia cells in vitro and sarcoma 180 cells and Ehrlich and Mep 2 ascites cells in vivo (18-20). We recently reported that SBL had a cytotoxic effect on various leukemia cells including MDR cells and showed that this cytotoxicity was induced through multiple apoptotic signaling pathways (21). Furthermore, data indicate that the SBL receptor (SBLR) may exist in the GEM on the cell surface (Tatsuta et al, unpublished data). In the present study, we investigated the involvement of Hsps in SBL-induced apoptosis, focusing on Hsp70 and Hsc70 that have been reported to exist in the GEM on the cell surface. 


\section{Materials and methods}

Materials. SBL was isolated by sequential chromatography on Sephadex G-75, DEAE-cellulose, hydroxyapatite and SP-Sepharose as described previously (13). The anti-SBL antibody was established in our laboratory. The anti-caspase-3 antibody was purchased from BD Biosciences (Franklin Lakes, NJ, USA). The anti-Hsp70 and Hsc70 antibodies were purchased from Stressgen (Kampenhout, Belgium). The horseradish peroxidase (HRP)-conjugated anti-rabbit IgG antibody and the fluorescein isothiocyanate (FITC)-conjugated goat anti-rabbit antibody were purchased from Cedarlane (Hornby, Ontario, Canada). Quercetin was from Cayman Chemical Company (Ann Arbor, MI, USA).

Cell culture. Mouse leukemia P388 cells were obtained from the Cell Resource Center of Biomedical Research, Institute of Development, Aging and Cancer, Tohoku University (Sendai, Japan). Cells were routinely maintained in RPMI-1640 medium (Nissui Pharmaceutical Co. Ltd., Tokyo, Japan) supplemented with $10 \%$ fetal calf serum (FCS), penicillin $(100 \mathrm{U} / \mathrm{ml})$ and streptomycin $(100 \mu \mathrm{g} / \mathrm{ml})$ at $37^{\circ} \mathrm{C}$ in a $95 \%$ air and $5 \% \mathrm{CO}_{2}$ atmosphere.

Detection of DNA fragmentation. The cells $\left(2 \times 10^{5}\right.$ cells $\left./ \mathrm{ml}\right)$ were cultured in 96-well plates (100 $\mu \mathrm{l} /$ well). After treatment with SBL, the cells were collected by centrifugation, washed with PBS, then lysed with cell lysis buffer [50 mM Tris- $\mathrm{HCl}$ (pH 6.8), $10 \mathrm{mM}$ EDTA, $0.5 \%(\mathrm{w} / \mathrm{v})$ sodium N-lauroylsarcosinate]. The samples were incubated with RNase A (final concentration, $500 \mu \mathrm{g} / \mathrm{ml}$ ) for $30 \mathrm{~min}$ at $50^{\circ} \mathrm{C}$, before being digested with proteinase $\mathrm{K}$ (final concentration, $500 \mu \mathrm{g} / \mathrm{ml}$ ) for $30 \mathrm{~min}$ at $50{ }^{\circ} \mathrm{C}$. After the samples were electrophoresed on $1.8 \%$ agarose gel, DNA bands were visualized by ethidium bromide (EtBr) staining.

Western blotting. Whole cell lysate was prepared with extraction buffer $[10 \mathrm{mM}$ Tris- $\mathrm{HCl}(\mathrm{pH} 7.5), 150 \mathrm{mM} \mathrm{NaCl}$, $1 \%$ Triton $\mathrm{X}-100,5 \mathrm{mM}$ EDTA ( $\mathrm{pH} 8.0), 1 \mathrm{mM}$ phenylmethylsulfonyl fluoride (PMSF) and 1 tablet/10 $\mathrm{ml}$ protease inhibitor cocktail (Roche Applied Science, Indianapolis, IN, USA)]. Lysates from the membrane, cytosol and nuclear fractions were prepared by ProteoExtract Subcellular Proteome Extraction kit (Merck Millipore, Billerica, MA, USA). Soluble proteins were collected, and concentrations were measured by the DC protein assay kit (Bio-Rad, Richmond, CA, USA) in accordance with the manufacturer's instructions. Proteins were separated by SDS-PAGE and transferred to a polyvinylidene difluoride (PVDF) membrane (GE Healthcare, Little Chalfont, UK). The membrane was blocked using 5\% fat-free skim milk for $1 \mathrm{~h}$. After the membrane was washed with TBST [20 mM Tris- $\mathrm{HCl}$ (pH 7.6), $137 \mathrm{mM} \mathrm{NaCl}, 0.05 \%$ Tween-20], primary and secondary antibodies were added to the membrane, respectively. The proteins on the membrane were detected using ECL western blotting detection reagents (GE Healthcare). The intensity of the bands was calculated by Quantity One software (Bio-Rad).

Flow cytometric analysis of SBLR, Hsp70 and Hsc70. For detection of SBLR, cells were treated with SBL for $30 \mathrm{~min}$ at

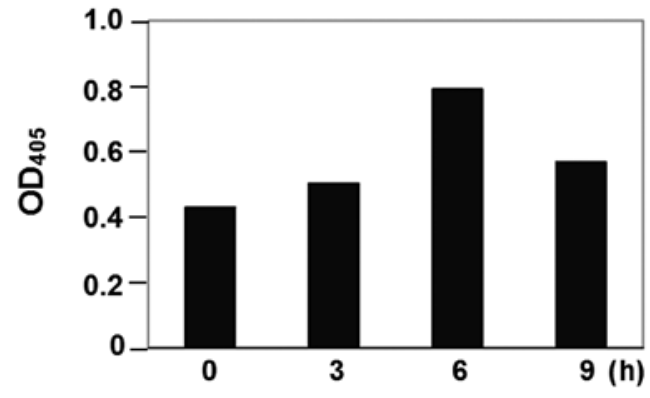

Figure 1. Effect of SBL on the activation of caspase-3 in P388 cells. Cells were treated with SBL $(2 \mu \mathrm{M})$ for indicated time. Caspase- 3 activity was examined by use of DEVD-pNA. SBL, sialic acid-binding lectin.

$4^{\circ} \mathrm{C}$, washed with PBS, and incubated with the anti-SBL antibody for $30 \mathrm{~min}$ at $4^{\circ} \mathrm{C}$. Cells were washed with PBS, and then FITC-labeled anti-rabbit IgG was added and incubated for $30 \mathrm{~min}$ at $4^{\circ} \mathrm{C}$. For detection of Hsp70 and Hsc70, cells were treated with anti-Hsp70 and anti-Hsc70 antibodies for $30 \mathrm{~min}$ at $4^{\circ} \mathrm{C}$, washed with PBS and incubated with FITC-labeled anti-rabbit $\mathrm{IgG}$ for $30 \mathrm{~min}$ at $4^{\circ} \mathrm{C}$, respectively. Fluorescence intensity was determined using a FACSCalibur flow cytometer (Becton-Dickinson).

Reverse transcription and polymerase chain reaction $(R T-P C R)$. Total cellular RNA was isolated from the cells using TRIzol reagent (Invitrogen Life Technologies, Carlsbad, CA, USA). Reverse transcription (RT) was performed using ReverTra Ace (Toyobo, Osaka, Japan) with total RNA (1 $\mu \mathrm{g})$ and oligo $(\mathrm{dT})_{12-18}$ primers. The RT reaction mixture $(1 \mu \mathrm{l})$ was subjected to PCR for 25, 40 and 30 cycles for GAPDH, Hsp70 and Hsc70, respectively, in a final volume of $20 \mu 1$ of Taq DNA polymerase (1.25 U) (ABgene, Epsom, UK) and gene-specific forward and reverse primers for each gene. After initial denaturation at $94^{\circ} \mathrm{C}$ for $2 \mathrm{~min}$, each of the cycles consisted of $94^{\circ} \mathrm{C}$ for $30 \mathrm{sec}, 50^{\circ} \mathrm{C}$ for $30 \mathrm{sec}$ and $72^{\circ} \mathrm{C}$ for $30 \mathrm{sec}$. The PCR products were separated on $1.5 \%$ agarose gel, and the bands were visualized with EtBr staining. The intensity of bands was calculated by Quantity One software.

Measurement of cell viability. Cell viability was determined by the trypan blue dye exclusion assay. The cells $\left(2 \times 10^{5}\right.$ cells/ $\mathrm{ml})$ were cultured with SBL $(2 \mu \mathrm{M})$ and/or quercetin $(5 \mu \mathrm{M})$ in 96-well plates. After treatment with SBL and/or quercetin, the cells were stained with $0.25 \%$ trypan blue, and both viable and nonviable cells were counted.

Statistical analysis. Each experiment was performed at least in triplicate. The results are expressed as the means \pm standard deviation. Statistical analysis was performed using unpaired Student's t-tests; $\mathrm{P}<0.05$ was considered to indicate a statistically significant difference.

\section{Results}

SBL-induced apoptosis in P388cells. We recently reported that SBL induces apoptosis in various leukemia cell lines. In human leukemia Jurkat cells, typical apoptotic morphological change 
A

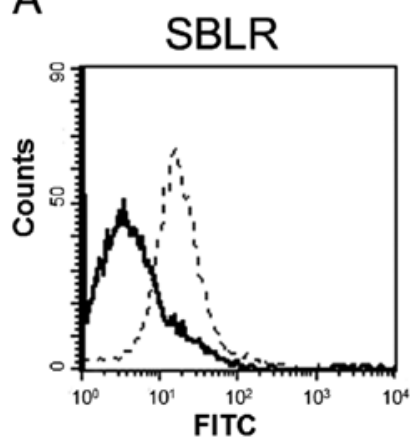

B

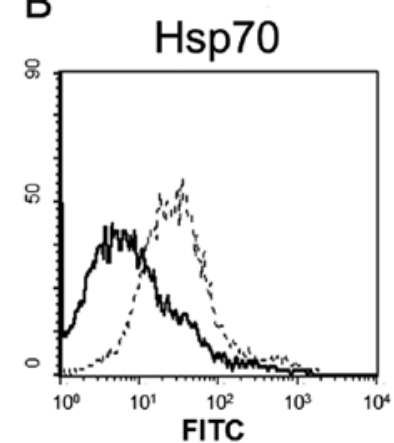

C

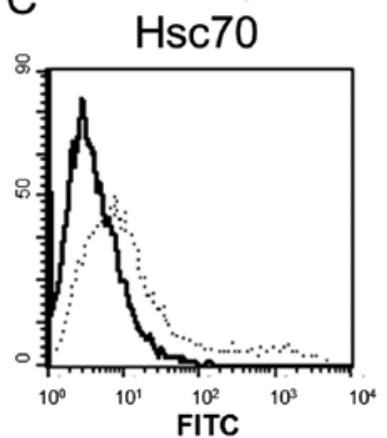

Figure 2. Flow cytometric analysis of heat shock proteins on the P388 cell surface. (A) SBLR, (B) Hsp70 and (C) Hsc70 on the P388 cell surface were analyzed by flow cytometry using respective antibodies (dotted line). Solid line indicates control cells for each experiment. SBLR, SBL receptor; SBL, sialic acid-binding lectin.
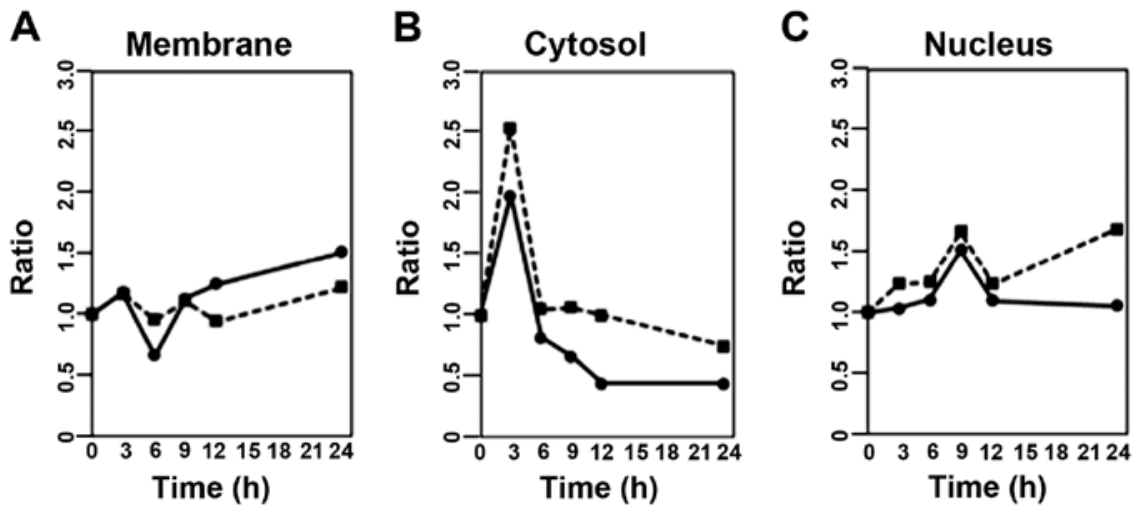

Figure 3. Distribution of Hsp70 and Hsc70 in the SBL-treated P388 cells. Each fraction [(A) membrane/organelle; (B) cytosol and (C) nuclear] was extracted from SBL-treated P388 cells. The levels of Hsps were detected by western blot analysis. Hsp70, solid line; Hsc70, dotted line. SBL, sialic acid-binding lectin; Hsps, heat shock proteins.

such as karyorrhexis, nuclear condensation and fragmentation, or apoptotic biological changes such as phosphatidylserine (PS) externalization, activation of caspases, DNA fragmentation were observed after treatment with SBL (21). In the present study, the apoptosis-inducing effect of SBL in P388 cells was analyzed by the detection of activated caspase- 3 . Caspase- 3 activity was monitored by use of DEVD-pNA. The activity of caspase-3 was observed and maximized at $6 \mathrm{~h}$ of treatment (Fig. 1). As a concequence, SBL-induced apoptosis in P388 cells and the execution process may start as early as $6 \mathrm{~h}$.

Expression of SBLR, Hsp70 and Hsc70 on the P388 cell membrane. It has been suggested that SBL binds to the cell membrane to exert its antiproliferative effects which indicates the existence of SBLR. We analyzed the involvement of Hsps in SBL-induced apoptosis. We analyzed the expression of SBLR, Hsp70 and Hsc70 on the cell membrane by flow cytometric analysis. The results showed that both Hsp70 and Hsc70 were expressed on the cell membrane as well as SBLR (Fig. 2).

Distribution of Hsp70 and Hsc70 in SBL-treated P388 cells. Our next experiment was designed to elucidate the localization of Hsp70 and Hsc70 after stimulation of SBL in P388 cells. After treatment with SBL, the cells were lysed and fractionated into the membrane, cytosol and nuclear fractions, and then the amounts of Hsp70 or Hsc70 were analyzed by western blotting. The results showed that Hsp70 in the membrane fraction at $6 \mathrm{~h}$ of treatment was decreased $34 \%$ when compared to the $0 \mathrm{~h}$-control and then gradually increased(Fig. 3A). In the cytosol fraction, both Hsp70 and Hsc70 were transiently increased at $3 \mathrm{~h}$ of treatment, and a transient increase was also observed in the nuclear fraction at $9 \mathrm{~h}$ of treatment (Fig. 3B and C). After treatment with SBL, the localization of Hsp70 and Hsc70 was altered when compared to that in the cells without SBL treatment. Notably, SBL-induced activation of caspase-3 began to be observed, just after the amounts of Hsp70 and Hsc70 in the cytosol fraction reached maximum levels.

Effect of quercetin on expression of Hsp70 or Hsc70. To clarify the relationship between Hsp70 and Hsc70 in SBL-induced apoptosis, we treated $\mathrm{P} 388$ cells with quercetin, a known bioflavonoid which decreases the expression of Hsp70. Treatment with quercetin for $12 \mathrm{~h}$ resulted in a $60 \%$ reduction in $\mathrm{Hsp} 70$ at the mRNA level and a $50 \%$ reduction at the protein level (Fig. 4). By contrast, quercetin did not affect the expression of Hsc70 at the mRNA or protein level.

Effect of quercetin on the binding of SBL to P388 cells. As we confirmed that quercetin decreases the expression of Hsp70, 
A

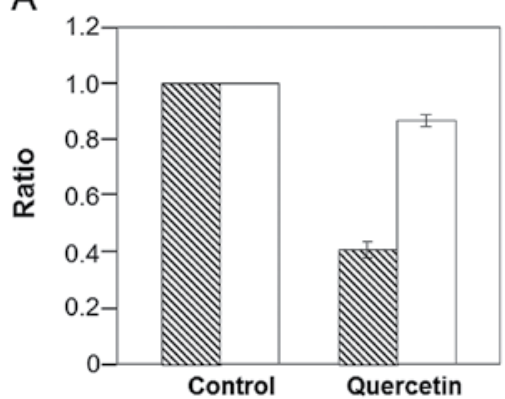

B

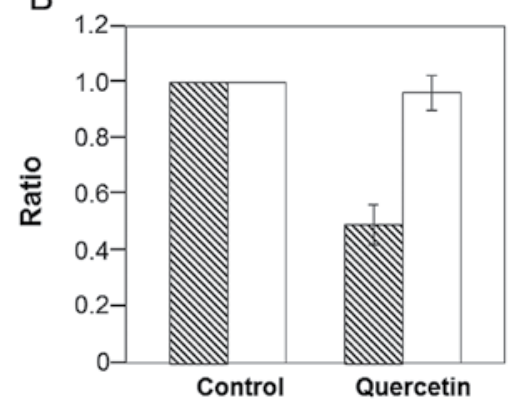

Figure 4. Effect of quercetin on mRNA expression and protein levels of Hsp70 and Hsc70. Cells were treated with quercetin (5 $\mu \mathrm{M})$ for 12 h. Expression of Hsp70 (striped column) and Hsc70 (white column) at the (A) mRNA and (B) protein level was determined by RT-PCR and western blot analysis, respectively.

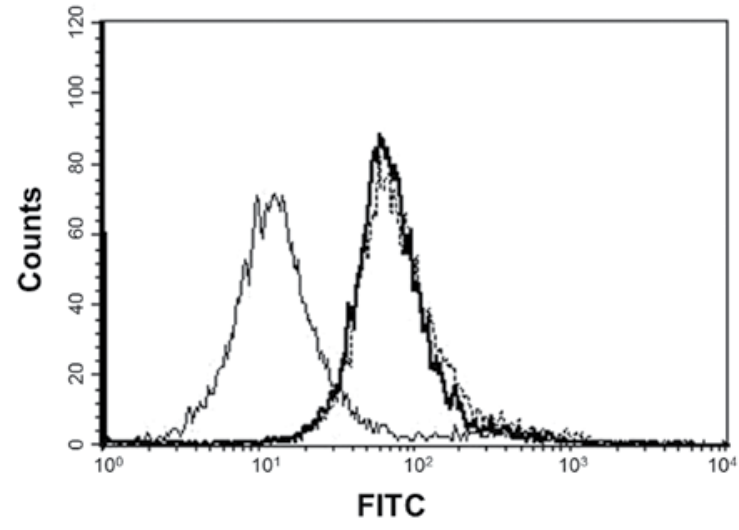

Figure 5. Effect of quercetin on the binding of SBL to P388 cells. Cells were treated with (bold line) or without (dotted line) quercetin $(5 \mu \mathrm{M})$ for $12 \mathrm{~h}$. After treatment with SBL and the anti-SBL antibody as described in Materials and methods, the cells were analyzed by FACSCalibur. Control, thin black line. SBL, sialic acid-binding lectin.

we next analyzed whether suppression of Hsp70 has an effect on SBL function. We assessed whether the binding of SBL to its predicted receptor was affected by treatment with quercetin. The result showed that quercetin did not affect the binding of SBL (Fig. 5), indicating that decreased expression of Hsp70 did not affect the binding of SBL to its receptor.

Effect of quercetin on SBL-induced cytotoxicity. The next experiment was performed to eludicate the effect of quercetin on SBL-induced cytotoxicity. After treatment with quercetin, SBL-induced cytotoxicity or apoptosis was analyzed by trypan blue dye exclusion assay and DNA fragmentation analysis. The result showed that both the antiproliferative effect of SBL and SBL-induced DNA fragmentation were inhibited by treatment with quercetin (Fig. 6A and B). These results suggest the Hsp70 may play a significant role in the antitumor effect induced by SBL.

\section{Discussion}

Various members of the RNase family are known for their cytotoxic effects and have attracted attention as a new type of anticancer drug. The proposed mechanism of ribonuclease-induced cytotoxicity is i) cell surface binding and internalization, ii) translocation to the cytosol, iii) escape

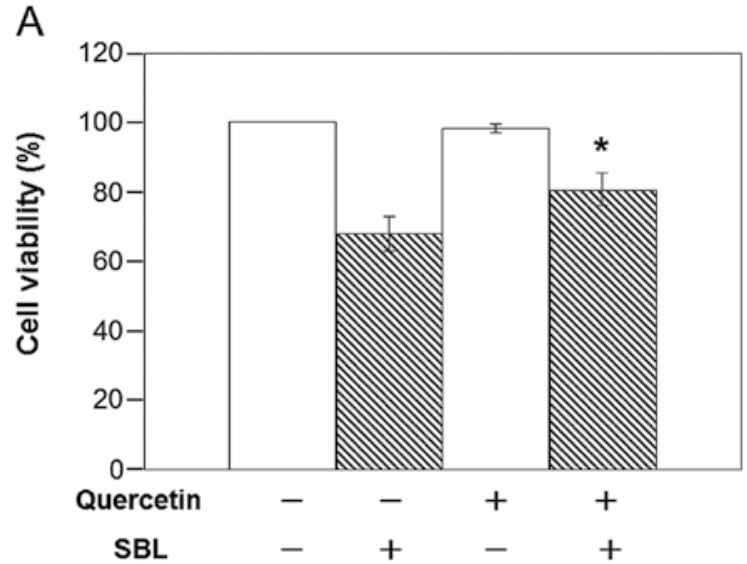

B

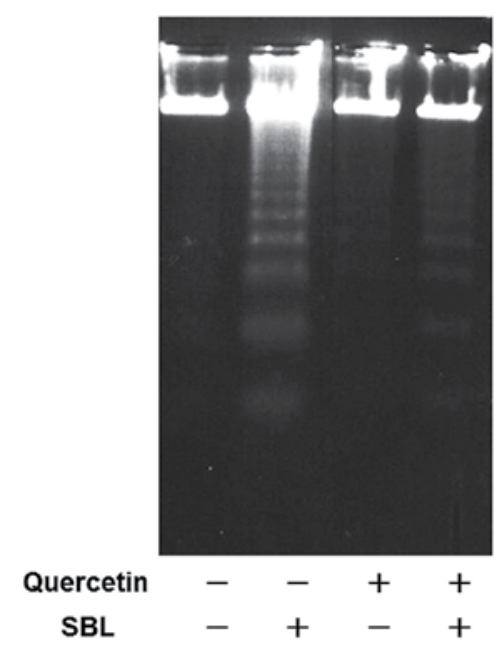

Figure 6. Effect of quercetin on SBL-induced cytotoxicity. After pretreatment with quercetin $(5 \mu \mathrm{M})$ for $12 \mathrm{~h}$, the cells were incubated with SBL $(2 \mu \mathrm{M})$ for 24 h. (A) The viable cells were counted by trypan blue dye exclusion assay ${ }^{*} \mathrm{P}<0.05$ vs. SBL alone. (B) Agarose gel electrophoresis of DNA extracted from SBL-treated P388 cells. SBL, sialic acid-binding lectin.

from the cytosolic ribonuclease inhibitor protein (RI), and iv) degradation of cellular RNA. Differences in the efficiency in any of these steps may affect cell susceptibility (22). SBL is a multifunctional protein which has lectin activity, ribonuclease activity and antitumor activity. The selective effect of SBL on cancer cells is due to its selective binding to tumor cells, as 
sialidase treatment of cells was found to abolish tumor cell agglutination and the antiproliferative effect induced by SBL, and the existence of SBLR in the GEM on the cell surface has been suggested (13). In the present study, we investigated the possible involvement of Hsp70 and Hsc70 known Hsps which exist on the GEM, in SBL-induced apoptosis.

We found that Hsp70 and Hsc70 were expressed on the P388 cell surface as well as SBLR (Fig. 2). Distribution of Hsp70 and Hsc70 was analyzed after treatment with SBL, and expression of Hsp70 and Hsc70 in the cytosol was dramatically increased immediately prior to the execution of apoptosis in SBL-treated P388 cells (Figs. 1 and 3). Next we studied the functional relationship of Hsps and the cytotoxic activity of SBL by the use of quercetin. Quercetin was previously found to decrease the expression of Hsp70 at the mRNA level by inhibiting the activation of HSF1 (23). The expression of Hsp70 was decreased at both the mRNA and protein levels in the quercetin-treated cells (Fig. 4). We found that binding of SBL to P388 cells was not affected by a decrease in Hsp70 expression by quercetin. The result indicates that Hsp70 itself may not be the receptor for SBL (Fig. 5). However, further study revealed that a decrease in Hsp70 by quercetin inhibited both SBL-induced cytotoxicity and apoptosis (Fig. 6), suggesting the important role that Hsp70 plays in SBL-induced apoptosis.

Various reports have indicated a relationship between Hsps, particularly the Hsp70 family, and various receptors on the cell surface. It was reported that Hsp70 and Hsc70 possibly interact with CD14, CD40 and the toll-like receptor family members (24-26). Notably, Guerrero and Moreno (27) reported that Hsc70 and integrin $\alpha v \beta 3$ formed a complex in the GEM and act as a receptor for rotavirus and may participate in the process of adsorption and penetration of the viruses into cells. In the present study, we showed that binding of SBL was not affected by a decrease in the expression of Hsp70, but an attenuated induction of apoptosis was noted. It is possible that Hsps on the P388 cell surface may interact with SBLR or participate in the penetration of SBL into cells, and may affect the cytotoxicity of SBL, as cell susceptibility to RNase can be affected by binding as well as the internalization or translocation of RNases as described above. Since the expression of Hsc70 was not affected by quercetin, studies to clarify the possible involvement of Hsc70 or other Hsps in the function of SBL will be undertaken.

In summary, the present study demonstrated that Hsp70 and Hsc70 are expressed on the P388 cell surface as well as SBLR, and their expression levels are markedly increased in the cytosol immediately prior to the execution of apoptosis following SBL treatment. A functional study of Hsp70 revealed that decreased expression of Hsp70 suppressed the apoptosis induced by SBL. It is suggested, for the first time, that Hsps participate in the antitumor effect of cytotoxic RNases.

\section{Acknowledgements}

This study was supported in part by a Grant-in-Aid from the 'Academic Frontier' Project for Private Universities from the Ministry of Education, Culture, Sports, Science and Technology of Japan.

\section{References}

1. Snoeckx LH, Cornelussen RN, Van Nieuwenhoven FA, Reneman RS and Van Der Vusse GJ: Heat shock proteins and cardiovascular pathophysiology. Physiol Rev 81: 1461-1497, 2001.

2. Mosser DD, Caron AW, Bourget L, Denis-Larose C and Massie B: Role of the human heat shock protein hsp70 in protection against stress-induced apoptosis. Mol Cell Biol 17: 5317-5327, 1997.

3. Beere HM, Wolf BB, Cain K, Mosser DD, Mahboubi A, Kuwana T, Tailor P, et al: Heat-shock protein 70 inhibits apoptosis by preventing recruitment of procaspase- 9 to the Apaf-1 apoptosome. Nat Cell Biol 2: 469-475, 2000.

4. Liossis SN, Ding XZ, Kiang JG and Tsokos GC: Overexpression of the heat shock protein 70 enhances the TCR/CD3- and Fas/Apo-1/CD95-mediated apoptotic cell death in Jurkat T cells. J Immunol 158: 5668-5675, 1997.

5. Welch WJ: Mammalian stress response: cell physiology, structure/function of stress proteins, and implications for medicine and disease. Physiol Rev 72: 1063-1081, 1992.

6. Bausero MA, Page DT, Osinaga E and Asea A: Surface expression of Hsp25 and Hsp72 differentially regulates tumor growth and metastasis. Tumour Biol 25: 243-251, 2004.

7. Calderwood SK, Mambula SS, Gray PJ Jr and Theriault JR: Extracellular heat shock proteins in cell signaling. FEBS Lett 581: 3689-3694, 2007.

8. Sugawara S, Kawano T, Omoto T, Hosono M, Tatsuta T and Nitta K: Binding of Silurus asotus lectin to Gb3 on Raji cells causes disappearance of membrane-bound form of HSP70. Biochim Biophys Acta 1790: 101-109, 2009.

9. Chen S, Bawa D, Besshoh S, Gurd JW and Brown IR: Association of heat shock proteins and neuronal membrane components with lipid rafts from the rat brain. J Neurosci Res 81: 522-529, 2005.

10. Broquet AH, Thomas G, Masliah J, Trugnan G and Bachelet M: Expression of the molecular chaperone Hsp70 in detergentresistant microdomains correlates with its membrane delivery and release. J Biol Chem 278: 21601-21606, 2003.

11. Kawauchi H, Sakakibara F and Watanabe K: Agglutinins of frog eggs: a new class of proteins causing preferential agglutination of tumor cells. Experientia 31: 364-365, 1975.

12. Sakakibara F, Kawauchi H, Takayanagi G and Ise H: Egg lectin of Rana japonica and its receptor glycoprotein of Ehrlich tumor cells. Cancer Res 39: 1347-1352, 1979.

13. Nitta K, Takayanagi G, Kawauchi H and Hakomori S: Isolation and characterization of Rana catesbeiana lectin and demonstration of the lectin-binding glycoprotein of rodent and human tumor cell membranes. Cancer Res 47: 4877-4883, 1987.

14. Titani K, Takio K, Kuwada M,Nitta K, Sakakibara F, Kawauchi H, Takayanagi G and Hakomori S: Amino acid sequence of sialic acid binding lectin from frog (Rana catesbeiana) eggs. Biochemistry 26: 2189-2194, 1987.

15. Kamiya Y, Oyama F, Oyama R, Sakakibara F, Nitta K, Kawauchi $\mathrm{H}$, Takayanagi $\mathrm{Y}$ and Titani $\mathrm{K}$ : Amino acid sequence of a lectin from Japanese frog (Rana japonica) eggs. J Biochem 108: 139-143, 1990.

16. Nitta K, Oyama F, Oyama R, Sekiguchi K, Kawauchi H, Takayanagi Y, Hakomori S and Titani K: Ribonuclease activity of sialic acid-binding lectin from Rana catesbeiana eggs. Glycobiology 3: 37-45, 1993.

17. Okabe Y, Katayama N, Iwama M, Watanabe H, Ohgi K, Irie M, Nitta K, et al: Comparative base specificity, stability, and lectin activity of two lectins from eggs of Rana catesbeiana and $R$. japonica and liver ribonuclease from $R$. catesbeiana. J Biochem 109: 786-790, 1991.

18. Nitta K, Ozaki K, Ishikawa M, Furusawa S, Hosono M, Kawauchi H, Sasaki K, et al: Inhibition of cell proliferation by Rana catesbeiana and Rana japonica lectins belonging to the ribonuclease superfamily. Cancer Res 54: 920-927, 1994.

19. Nitta K, Ozaki K, Tsukamoto Y, Furusawa S, Ohkubo Y, Takimoto H, Murata R, et al: Characterization of a Rana catesbeiana lectin-resistant mutant of leukemia P388 cells. Cancer Res 54: 928-934, 1994.

20. Nitta K, Ozaki K, Tsukamoto Y, Hosono M, Ogawakonno Y, Kawauchi H, Takayanagi Y, et al: Catalytic lectin (leczyme) from bullfrog (Rana catesbeiana) eggs: Mechanism of tumoricidal activity. Int J Oncol 9: 19-23, 1996.

21. Tatsuta T, Hosono M, Sugawara S, et al: Sialic acid-binding lectin (leczyme) induces caspase-dependent apoptosis-mediated mitochondrial perturbation in Jurkat cells. Int J Oncol 43: 1402-1412, 2013. 
22. Haigis MC, Kurten EL and Raines RT: Ribonuclease inhibitor as an intracellular sentry. Nucleic Acids Res 31: 1024-1032, 2003.

23. Hosokawa N, Hirayoshi K, Kudo H, Takechi H, Aoike A, Kawai K and Nagata K: Inhibition of the activation of heat shock factor in vivo and in vitro by flavonoids. Mol Cell Biol 12: 3490-3498: 1992.

24. Asea A, Kraeft SK, Kurt-Jones EA, Stevenson MA, Chen LB, Finberg RW, Koo GC and Calderwood SK: HSP70 stimulates cytokine production through a CD14-dependant pathway, demonstrating its dual role as a chaperone and cytokine. Nat Med 6: 435-442, 2000.
25. Becker T, Hartl FU and Wieland F: CD40, an extracellular receptor for binding and uptake of Hsp70-peptide complexes. J Cell Biol 158: 1277-1285, 2002.

26. Asea A, Rehli M, Kabingu E, Boch JA, Bare O, Auron PE, Stevenson MA and Calderwood SK: Novel signal transduction pathway utilized by extracellular HSP70: role of toll-like receptor (TLR) 2 and TLR4. J Biol Chem 277: 15028-15034, 2002.

27. Guerrero CA and Moreno LP: Rotavirus receptor proteins Hsc70 and integrin $\alpha v \beta 3$ are located in the lipid microdomains of animal intestinal cells. Acta Virol 56: 63-70, 2012. 